\title{
Regarding "The orthopaedic and traumatology scenario during Covid-19 outbreak in Italy: chronicles of a silent war" a Mexican perspective
}

\author{
Abraham Guadalupe Espinosa-Uribe ${ }^{1,2}$ (D) Juan Carlos Gonzalez-Saldivar ${ }^{1,2} \cdot$ Luis Andrés Valverde-Galindo ${ }^{1,2}$. \\ Javier Meza-Flores ${ }^{1,2} \cdot$ Jorge Gutiérrez-de la $\mathrm{O}^{1,3}$
}

Received: 20 July 2020 / Accepted: 23 July 2020 / Published online: 31 July 2020

(C) SICOT aisbl 2020

Keywords Covid-19 · Pandemic $\cdot$ Social mobility · Orthopedics · Traumatology

To the editor,

We sincerely applaud the work done by Benazzo et al. [1] analyzing it with deep concern. This observational study describes the drastic activity decrease of 15 Italian orthopaedic centres during the COVID-19 outbreak as a consequence of strict confinement imposed by the Italian authorities.

It is important to mention that at the time of writing this communication, Mexico has overtaken Italy in the death-toll from COVID19 [2] with a few controversies in the management of the pandemic, focusing on social mobility the government has urged people to "stay home", although quarantines have not been strictly enforced [3] during the last four months.

With preliminary results, our team has also documented reductions comparing hospitalizations in 2020 with the same periods in 2018 of $21 \%, 66 \%, 57 \%$, and $45 \%$ as well as 2019 of $24 \%, 66 \%, 55 \%$, and $33 \%$, respectively for March, April, May, and June (reopening) in our group of four private hospitals being evaluated (Christus Muguerza Alta Especialidad,

Abraham Guadalupe Espinosa-Uribe

abm.55@hotmail.com

1 Departamento de Ortopedia y traumatología, Hospital Christus Muguerza, Alta Especialidad Miguel Hidalgo 2525, Obispado, 64060 Monterrey, Nuevo León, Mexico

2 Escuela de Medicina, Especialidades Médicas, Universidad de Monterrey, Av. Ignacio Morones Prieto 4500, Jesús M. Garza, 66238 San Pedro Garza García, Nuevo Leon, Mexico

3 School of Medicine, Human Anatomy Department, Universidad Autónoma de Nuevo León, Avenida Francisco I. Madero y Gonzalitos s/n Colonia Mitras Centro C.P, 64460 Monterrey, Nuevo León, Mexico
Hospital Sur, Hospital General Conchita and Hospital Vidriera) in Monterrey, Mexico.

Our results partially correspond with the results by Benazzo et al. [1]; however, differences in percentages of decreased activity are related to how strict confinement has been managed by Italian authorities compared with that of Mexican Federal health authorities, as well as the population cultural features [3]. Therefore, the less strict the management and the more laxity of quarantine measures implies more social mobility with the increase in accidents as well as the number of COVID-19 infections and dead toll [4] with the consequent socioeconomic, medical, and orthopaedic implications, as well as the decrease in the learning curves of residents [5] and the number of infections among colleagues.

We agree that lockdown and quarantine measures are deeply related to the decrease in the number of accidents as well as the number of patients received for care in the emergency departments.

Finally, we appreciate the work carried out by Benazzo et al., in which in an important multicenter study, the decrease of surgical procedures in orthopaedic and trauma services is described as a consequence of progressive closing of commercial activities and industries due to quarantine measures in a setting of national disaster by COVID19.

Authors' contributions All authors contributed to the manuscript and data collection in the different hospitals mentioned. The first draft of the manuscript was written by Espinosa-Uribe AG, and all authors commented on later versions of the manuscript. All authors read and approved the final manuscript.

\section{Compliance with ethical standards}

Conflict of interest The authors declare that they have no conflict of interest. 


\section{References}

1. Benazzo F, Rossi SMP, Maniscalco P et al (2020) The orthopaedic and traumatology scenario during Covid-19 outbreak in Italy: chronicles of a silent war. Int Orthop. https://doi.org/10.1007/s00264-02004637-3

2. Culp WC (2020) Coronavirus disease 2019 situation report - 177. In: PAHO - WHO. https://www.who.int/docs/default-source/ coronaviruse/situation-reports/20200715-covid-19-sitrep-177.pdf? sfvrsn=b1a193f3 2. Accessed 15 Jul 2020

3. Agren D (2020) Mexican President López Obrador draws doctors' ire President. Lancet 395:19-21
4. Ricardo-Azanza CL, Vargas-Hernandez EA (2020) The risk of lifting COVID-19 confinement in Mexico. medRxiv. https://doi. org/10.1101/2020.05.28.20115063

5. Chang D-G, Park J-B, Baek GH et al (2020) The impact of COVID19 pandemic on orthopaedic resident education: a nationwide survey study in South Korea. Int Orthop. https://doi.org/10.1007/s00264020-04714-7

Publisher's note Springer Nature remains neutral with regard to jurisdictional claims in published maps and institutional affiliations. 